\title{
O impacto da gestão documental nos arquivos de engenharia e arquitetura: uma análise do arquivo da DIPOP do Instituto Federal de Educação, Ciência e Tecnologia de Sergipe
}

\section{The document management impact on engineering and architecture's archives: an analysis of dipop's archive of the Federal Institute of Education, Science and Technology of Sergipe}

\author{
Franklin Gabriel Souza dos Santos ${ }^{1}$, Manuela do Nascimento Silva ${ }^{2}$, Valéria Aparecida Bari ${ }^{3}$ \\ ${ }^{1}$ Universidade Federal de Sergipe (UFS), Aracaju, Sergipe, Brasil. ORCID: https://orcid.org/0000-0002-4149-9077 \\ 2 Instituto Federal de Sergipe (UFS), Aracaju, Sergipe, Brasil. ORCID: https://orcid.org/0000-0003-2464-3142 \\ ${ }^{3}$ Universidade Federal de Sergipe (UFS), Aracaju, Sergipe, Brasil. ORCID: https://orcid.org/0000-0003-2871-5780
}

Autor para correspondência/Mail to: Manuela do Nascimneto Silva, manueladocx@gmail.com

Recebido/Submitted: 12 de julho de 2020; Aceito/Approved: 21 de dezembro de 2020

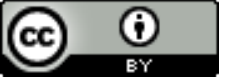

Copyright (c) 2021 Santos, Silva \& Bari. Todo o conteúdo da Revista (incluindo-se instruções, política editorial e modelos) está sob uma licença Creative Commons Atribuicão 4.0 Internacional. Ao serem publicados por esta Revista, os artigos são de livre uso em ambientes educacionais, de pesquisa e não comerciais, com atribuição de autoria obrigatória. Mais informações em http://revistas.ufpr.br/atoz/about/submissions\#copyrightNotice.

\begin{abstract}
Resumo
Introdução: a Gestão da Informação e do Conhecimento é uma atividade especializada no cotidiano de um arquivo, seja ele público ou privado, caracterizando-o como uma unidade de informação. Este artigo tem por objetivo ressaltar o impacto que uma gestão documental de qualidade tem sobre um arquivo especializado, sob os princípios da gestão da informação e do conhecimento, a busca pela mediação da informação documental implícita e explícita e o cumprimento da função social da universidade pública e de qualidade. Metodologia: foi utilizado como base para a análise descritiva o arquivo da Diretoria de Planejamento de Obras e Projetos do Instituto Federal de Educação, Ciência e Tecnologia de Sergipe. O artigo também fez uso da pesquisa bibliográfica de revisão narrativa de literatura, baseada na análise de livros, artigos, monografias, legislação e manuais arquivísticos, entre outros trabalhos. Resultados: aplicação da Gestão da Informação e do Conhecimento, gestão documental e mediação informacional especializada no arquivo da Diretoria de Planejamento de Obras e Projetos, alterou positivamente a concretização de objetivos informacionais no Arquivo Especializado em Arquitetura e Engenharia. Conclusão: a gestão da unidade de informação da Diretoria de Planejamento de Obras e Projetos, otimizou o processo de recuperação da informação, respeitando o perfil dos usuários, a função especializada em Arquitetura e Engenharia, a função social do Instituto Federal de Educação, Ciência e Tecnologia de Sergipe, disseminando a informação especializada para a sociedade e construindo conhecimento especializado com impactos sociais para além da estrutura institucional.
\end{abstract}

Palavras-chave: Gestão da Informação e do Conhecimento; Gestão Documental; Arquivo Especializado; Recuperação da Informação.

\begin{abstract}
Introduction: information and knowledge management is a specialized activity in the daily life of an archive, be it public or private, characterizing it as an information unit. This article aims to highlight the impact that quality document management has on a specialized archive, under the principles of information and knowledge management, the search for the mediation of implicit and explicit document information and the fulfillment of the social function of the public university and quality. Method: as a basis for descriptive analysis, the file of the Directorate of Planning of Works and Projects of the Federal Institute of Education, Science and Technology of Sergipe. The article also made use of the literature search for narrative literature review, based on the analysis of books, articles, monographs, legislation and archival manuals, among other works. Results: the application of Information and Knowledge Management, Document Management and specialized information mediation in the Directorate of Planning of Works and Projects archive, positively changed the achievement of informational objectives in the Specialized Archive in Architecture and Engineering. Conclusions: the management of the Directorate of Planning of Works and Projects information unit, optimized the information retrieval process, respecting the profile of users, the function specialized in Architecture and Engineering, the social function of Federal Institute of Education, Science and Technology of Sergipe, disseminating specialized information to society and building specialized knowledge with social impacts beyond the institutional structure.
\end{abstract}

Keywords: Information and Knowledge Management; Document Management; Specialized Archive; Information Retrieval.

\section{INTRODUÇÃO}

Os arquivos têm o objetivo de organizar todos os documentos produzidos por uma instituição, seja ela pública ou privada, para melhor organizar e tratar a informação de modo que facilite a sua busca e recuperação. Nessa perspectiva, este artigo visa descrever as atividades desenvolvidas na organização do Arquivo Especializado Engenharia e Arquitetura da Diretoria de Planejamento de Obras e Projetos (DIPOP) do Instituto Federal de Educação, Ciência e Tecnologia de Sergipe (IFS), localizado na cidade de Aracaju. Mais especificamente, buscou-se mostrar os principais benefícios, impactos e contribuições que um arquivo devidamente organizado pode oferecer para o setor em que se encontra e, principalmente, identificar como a organização correta pode contribuir para a precisão e agilidade na hora de disponibilizar um documento para o usuário. O presente trabalho possui relevância social e aborda uma temática contemporânea, pois as técnicas utilizadas na organização do arquivo, bem como apresenta conceitos como: Gestão Documental; Arquivo; Arquivo Especializado; Informação; Acesso à 
Informação; Preservação da Informação; e descreve as atividades que vêm sendo desenvolvidas no arquivo da própria DIPOP, ambiente social inserido em uma Instituição Federal de Ensino.

O artigo foi dividido em cinco sessões. A primeira sessão abordou o conceito de Gestão Documental e Arquivo, mostrando suas definições de acordo com a Lei n. 8.159, de janeiro de 1991, e contextualizando as suas origens. Abordou-se, na primeira sessão, o conceito de Arquivos Especializados, com foco nos Arquivos de Engenharia e Arquitetura. Na segunda sessão, explorou-se o conceito e a definição de Informação; Acesso à Informação; Preservação da Informação. Na terceira sessão, apresentou-se o ambiente social da pesquisa, descrevendo um pouco mais sobre o IFS e sua história, o setor da DIPOP e o seu arquivo. Na quarta sessão, relatou-se as atividades que vêm sendo desenvolvidas no Arquivo da DIPOP. A quinta e última sessão faz a análise e discussão do que foram abordados nos capítulos anteriores. Além dessas cinco sessões, nas considerações finais, foram sintetizadas as principais constatações e retomados os objetivos primordiais do trabalho de pesquisa.

$\mathrm{O}$ artigo teve como objetivo principal apresentar o diferencial e as contribuições da gestão documental adequada em um arquivo especializado, viabilizando a existência da unidade de informação que contribui também para a gestão do conhecimento, confrontando-o com antigos paradigmas da custódia de informações em acúmulos. Como base conceitual, o artigo apresentou pesquisas especializadas, que indicam os possíveis efeitos de uma gestão documental de qualidade, como diferencial para as atividades de um arquivo, tanto no quesito de preservação e indexação da informação documental, como a custódia e guarda de originais para agilidade de busca e recuperação destes. A metodologia foi desenvolvida por meio de uma pesquisa de revisão narrativa de literatura, em que foram analisadas fontes especializadas de referências e de publicações científicas inseridas em bases de dados, a Biblioteca Digital Brasileira de Teses e Dissertações (BDTD), que integra em seus sistemas de informação teses e dissertações de várias áreas do saber e livros de referência sobre a temática. Foram utilizados sites específicos de legislação, como o Senado Federal e o Conselho Nacional de Arquivo (CONARQ). Utilizou-se ainda uma análise descritiva do arquivo da DIPOP.

\section{DA ARQUIVOLOGIA AOS ARQUIVOS ESPECIALIZADOS}

Segundo o fulcro legal que caracteriza a função social do documento e sua coleção, o arquivo pode ser definido como um ambiente, divisão ou estrutura onde se armazenam documentos, sejam eles textuais, iconográficos, cartográficos, filmográficos, em suportes tradicionais ou digitais. Importante destacar que para fins arquivísticos, conforme o Dicionário de Terminologia Arquivística do Arquivo Nacional, coleção é "o conjunto de documentos com características comuns, reunidas intencionalmente" (Arquivo Nacional, 2005, p. 52).

De acordo com a Lei n. 8.159, de 8 de janeiro de 1991 (1991), os arquivos são definidos como "conjuntos de documentos produzidos e recebidos por órgãos públicos, instituições de caráter público e entidades privadas, em decorrência do exercício de atividades específicas, bem como por pessoa física, qualquer que seja o suporte da informação ou a natureza dos documentos".

Não se pode falar sobre arquivo sem a pregressa conceituação dos termos Arquivologia e Arquivística, respectivamente cobrindo os aspectos científico e prático da gestão documental. A Arquivologia é uma área de conhecimento cuja finalidade é analisar as melhores formas, técnicas e boas práticas de se arquivar, preservar e organizar os documentos. A arquivologia é uma ciência que estuda as funções do arquivo. No rol desses conceitos, o arquivo emerge de uma necessidade inerente ao ser humano em manter sob guarda os documentos produzidos (Schmidt, 2012, p. 104).

Sob a concepção supra, o recente desenvolvimento da Arquivística relata que o conceito de arquivo remonta à antiguidade, quando os povos sinalizam de forma documental firmar acordos que abrangiam a administração pública, mediante a manutenção das relações e acordos entre os cidadãos, o poder político, o poder religioso e o poder econômico, existindo a necessidade civilizatória de preservação documental. Os protagonistas históricos, mediante a proteção das informações, interesses e narrativas registrados em documentos escritos, verificaram a necessidade de armazenar esses documentos produzidos, de modo protegido e centralizado, distinguindo-os de outros tesouros acumulados com finalidades distintas.

No chamado ciclo mineral da informação, os suportes eram inicialmente formados por registros em paredes naturais ou edificadas. À medida que a questão da portabilidade dos documentos passou a crescer em importância, foram desenvolvidos registros em cristais de rocha, tábuas de argila, esteiras de bambu, rolos de papiro ou de couro. O surgimento do papel veio cercado de desconfiança, visto a fragilidade e volatilidade do suporte, em vista da importância da informação documental. Superadas as questões do regime de informação, a aceitação do papel e também das fórmulas documentais nascidas na diplomacia, foi evidenciada a questão da gestão da informação e do conhecimento documental. Os locais caracterizados pela guarda das coleções de documentos passou também a prestar serviços de natureza informacional, voltados às partes interessadas, assim como garantir a integridade de originais e a emissão de vias documentais. O arquivo evoluiu de um ambiente de acumulação e coleção, que a princípio estas coleções compreendiam "documentos reunidos por razões científicas, artísticas, de entretenimento ou quaisquer outras que não administrativas" (Bellotto, 2007, p. 129), mas após serem abarcadas 
pelos fundos passaram a adquirir características que permitiram classificá-lo como unidade de informação. Com o advento das mídias digitais, completamente voláteis e com materialidade dividida entre suportes magnéticos (mídias), equipamentos (hardware) e aplicativos (software), o arquivo torna-se uma unidade de informação com características de rede social.

O Manual de Organização de Arquivos Correntes e Intermediários (Universidade Estadual de Campinas, 2005), define arquivo como uma entidade ou órgão administrativo que é responsável pela custódia, tratamento documental e pela utilização dos arquivos sob sua jurisdição. O respectivo manual também afirma que existem vários tipos de arquivos, sendo eles: públicos; privados (dentre os quais se enquadram os arquivos institucionais e pessoais); especiais (são aqueles em que as informações são registradas em suportes diferentes do papel, como fitas, filmes, dentre outros tipos de suportes); e especializados, que são aqueles em que são guardados documentos gerados por atividades especializadas, que normalmente precisam ser organizados por técnicas e materiais específicos, alguns exemplos desse tipo de arquivo são: arquivo médicos, de imprensa, jurídicos, de engenharia. Ressalta-se ainda que ao se distinguir arquivo público de privado, enquanto o arquivo público pode referir-se a determinada instituição e não somente constituir um fundo ou um conjunto documental. Quanto aos arquivos especiais, estes não possuem característica institucional embora tanto os especiais quanto os privados possam estar inseridos ou custodiados em arquivos públicos.

Neste trabalho, a ênfase do estudo será dos Arquivos de Engenharia e Arquitetura. Esse tipo de arquivo se enquadra na categoria de arquivos especializados, pois são arquivos que se concentram em áreas específicas na área de engenharia e arquitetura. Franklin (2007) entende que a natureza dos documentos relacionados a projetos nas áreas de engenharia os tornam específicos e os enquadram em documentos de arquivos especializados na área de engenharia. Em seu entendimento, o autor ainda identifica particularidades nestes documentos que o distinguem de outros acervos documentais, a saber: o tamanho do documento, que pode variar entre a folha A0 até a A4, os documentos com tamanhos não padronizados, entre outras. Nessa perspectiva, os autores Lutz e Somavilla (2016) compreendem que existe uma convergência conceitual entre os arquivos de engenharia e os arquivos especiais segundo a natureza dos documentos, visto que, as plantas e projetos da área de engenharia e arquitetura são documentos que possuem formas e suportes específicos, diferenciando-os como especiais no que tange ao seu tratamento, acondicionamento e condições de acesso e uso.

Nesta lógica, a Engenharia e a Arquitetura são áreas do conhecimento relativamente distintas, mas que estão relacionadas entre si porque os seus documentos compõem acervo comum de arquivo com documentos caracterizados como especiais no tratamento e no suporte como: plantas estruturais, projetos arquitetônicos, projetos elétricos, boletins de medições, dentre outros documentos, motivo que os enquadram na categoria de arquivo especializado. Os arquivos especializados têm um público bem específico porque geralmente constituem usuários especializados na área. Tomando-se por exemplo os arquivos de engenharia e arquitetura, em sua grande maioria serão engenheiros, arquitetos, técnicos especializados na ária que possuem conhecimento prévio especializado na busca pela informação, o que requer um maior conhecimento também pelo arquivista para que possa tratar a informação de forma que sua recuperação e acesso atenda a necessidade daquele usuário de forma eficiente e rápida, visto que, são informações utilizadas para tomada de decisão. Observar-se-á mais à frente, neste trabalho, um exemplo prático do que é um arquivo de engenharia e arquitetura.

\section{GESTÃO DOCUMENTAL NA CONTEMPORANIEDADE}

A convergência dos suportes de informação para as mídias digitais amplificou a questão da gestão documental no contexto da informação, trazendo um protagonismo que a transformou em elemento essencial para a produção do conhecimento. Este contexto aproximou o ciclo informacional a uma cultura que envolve as pessoas, Tecnologia de Informação e Comunicação (TIC) e a informação (Woida, 2008). O usuário unidade de informação passou a ocupar um lugar ativo com capacidade cognitiva, e o documento de arquivo, além da sua função orgânica, passou a conter elementos que podem contribuir para a construção do conhecimento. Fato que transformou os arquivos na atualidade em unidades com diferentes características informacionais e em ambientes propícios para a mediação da informação, na medida em que a mediação e a informação se relacionam diretamente com os fluxos informacionais e a partir deles proporciona relações de conhecimento, destacando a gestão documental como processo fundamental.

A Lei n. 8.159, de janeiro de 1991, considera a Gestão de Documentos "o conjunto de procedimentos e operações técnicas referentes à sua produção, tramitação, uso, avaliação e arquivamento em fase corrente e intermediária, visando a sua eliminação ou recolhimento para guarda permanente" (Lei n. 8.159, de 8 de janeiro de 1991, 1991).

A Gestão Documental surgiu como uma indispensável estratégia administrativa para otimização do uso das informações presentes nos mais variados tipos de suportes, sejam eles, papel, fotografia, microfilme, dentre outros (Moreno, 2008). Com isso, pode-se afirmar que a gestão documental é um fazer indispensável, que auxiliará no funcionamento de um arquivo, por suas atividades de controle e tratamento arquivístico. A origem da gestão documental data de meados do final século XIX, sendo seu desenvolvimento tanto teórico quanto prático, intensificado com o término da Segunda Guerra Mundial, pois o conflito mundial havia exposto a 
carência de metodologias e procedimentos para administrar a enorme produção de documentos da administração pública, considerando elementos como recuperação, sigilo, segurança, alçada, preservação e explicitação da informação socialmente produzida. As três fases da gestão documental surgiram para auxiliar na administração dos documentos e seus fluxos documentais, evitando, assim, gastos desnecessários e o acúmulo de documentos que não são essenciais para a empresa ou instituição. A gestão documental é dividida em três fases, sendo elas: produção, utilização e destinação.

A fase de produção de documentos é uma fase muito importante porque nela "o arquivista deve contribuir para que sejam criados apenas documentos essenciais à administração da instituição e evitadas duplicação e emissão de vias desnecessárias" (Paes, 2004, p. 42).

Essa fase ajudará a reduzir o volume de documentos, pois previne a criação de documentos que não sejam essenciais para a instituição e sua duplicação. Na segunda fase, fase de utilização, procura-se assegurar a rapidez e eficácia na disponibilização dos documentos para a instituição, englobando as atividades de protocolo, expedição, organização e arquivamento de documentos em fase corrente e intermediária, a elaboração de normas de acesso à documentação e a recuperação da informação (Paes, 2004). Na terceira e última fase, acontece a destinação dos documentos, selecionando-se os documentos a serem preservados ou descartados. O processo de destinação de documentos compreende a fase mais complexa, pois analisará e avaliará os documentos acumulados no arquivo, objetivando estabelecer os prazos de guarda e determinar quais documentos deverão ser arquivados no arquivo permanentemente e quais deverão ser eliminados por ter perdido o seu valor para a instituição (Paes, 2004). As três fases da gestão documental geram, assim, uma economia bastante significativa de recursos.

A informação gerada e gerida em suportes digitais trouxe uma quebra do paradigma custodial para o pós-custodial, no qual podemos verificar que outras preocupações se sobrepõem à otimização atingida por meio da gestão documental. Assim, a gestão da informação adotou visão que foi além das medidas de guarda, preservação, recuperação, teoria das idades e outros procedimentos vitais à existência do arquivo. O paradigma pós-custodial trouxe para a arquivologia, como ciência, um papel social mais relevante dentro da Sociedade da Informação e do Conhecimento, dialogando com outras áreas e englobando os arquivistas como profissionais da informação, os quais entendem o documento em um sentido mais amplo, de forma que:

Alguns profissionais da ciência da informação defendem que o objeto da área é "a informação registrada" e consideram o conhecimento ou o usuário elementos periféricos ao estudo da área. Contudo, se as ações para organizar, tratar e recuperar a informação têm um propósito, um contexto, um público, e só faz sentido relacionadas à essas variáveis, é impossível não estudar os fenômenos relacionados à compreensão, à apropriação e ao uso da informação por parte dos indivíduos. A gestão da informação e a gestão do conhecimento se preocupam com isso e desenvolvem metodologias que abrangem todos esses aspectos (Fadel et al., 2010, p.16).

Sendo assim, compreende-se que gerir uma unidade de informação especializada em Arquitetura e Engenharia não significa meramente uma organização de documentação específica, pois emergem preocupações com as diferentes mediações, caracterizando seu público interno e externo, seus usuários reais e potenciais, a natureza das informações e seu interesse público. Sobre todas essas preocupações, destacam-se as questões éticas, que abrangem a função social da Arquitetura, da Engenharia e da Ciência da Informação, na confluência de trabalhos e construção do conhecimento característicos dessa ambiência.

Sob o ponto de vista da mediação, temos o protagonismo dos profissionais especializados que utilizam a informação documental como insumo técnico-científico, sejam os Arquitetos, os Engenheiros ou os Administradores. Contudo, a existência do arquivo especializado também indica a presença de usuários que fiscalizam, verificam, contabilizam ou decidem atividades comerciais, sociais e produtivas na organização. Conhecer e desenvolver procedimentos e estratégias para disponibilizar a informação e o conhecimento de modo acessível, palatável, eficiente e enriquecedor, implica na familiarização com os usuários, seu regime de informação típico, níveis de autonomia e capacidade de apropriação de novos suportes linguagens. Nessa perspectiva estas unidades de informação possuem abrangência cultural, legal e de preservação da memória onde acontecem diferentes tipos de mediações, a saber:

O estudo da mediação levou-nos a dividi-la em dois grandes segmentos no âmbito do fazer do profissional da informação: a mediação implícita e a mediação explícita. Essa última ocorre nos espaços em que há, claramente, uma relação formal entre o usuário e o equipamento informacional. A mediação, nesse caso, é explícita e facilmente reconhecida em seus aspectos materiais, concretos. Quanto a mediação implícita, ela ocorre em cada ação do profissional da informação, tanto no armazenamento quanto no processamento e em outros trabalhos por ele desenvolvidos. Ela é implícita, pois está por trás dos objetivos desses setores. Qualquer ação, dentro do fazer do profissional da informação deve ter a apropriação da informação por parte do usuário, como seu objetivo principal. Sem isso, a ação justifica-se por si mesma e se consome em seu próprio espaço, em seu próprio fazer (Fadel et al., 2010, p.19).

Quando vislumbramos que o arquivo é, do ponto de vista da gestão da informação e do conhecimento, uma unidade de informação de conhecimento e cultura, verificamos que o conhecimento tácito desses usuários protagonizados 
não ingressa voluntariamente no sistema informacional. Sendo assim, as estratégias de formalização dos conteúdos tácitos e sua explicitação são procedimentos complexos, que são formalizados a partir da gestão de memória, que, no contexto do paradigma pós-custodial, pode-se afirmar:

As duas principais técnicas de gestão aplicadas nos arquivos (seleção e avaliação) dão forma, qualidade e direcionamento às informações, a partir de ações estruturadas em razões e vontades específicas, configurando, portanto, a subjetivação arquivística. Essas instituições tornam-se, por conseguinte, espaços estratégicos para o desenvolvimento de políticas oficiais da memória (Tavares \& Loureiro, 2017, p.78).

Entende-se que a memória é formalizada por meio das narrativas, as quais contribuem para a formalização documental dos fluxos informais e estes possuem uma maior relação ética porque envolvem o capital humano de uma organização. Ainda que possamos instruir as várias implicações no campo da ética dentro de uma organização, apenas os mais recentes movimentos sociais, articulados pelas redes sociais, aproximaram a gestão ética dos documentos. Inclusive, de profundos problemas de sonegação e ocultamento de informações de interesse público. Movimentações de controle da informação se dão em nível internacional e a obediência aos princípios gestores encontra-se na berlinda. No Brasil, a mais recente legislação busca a superação da responsabilidade custodial das grandes organizações, criando pressupostos de desmaterialização dos suportes tradicionais, sem a correspondente mediação das informações documentais contidas nas coleções. O Decreto n. 10.278 de 18 de março de 2020 (2020), autoriza a digitalização de acervos públicos e privados, sem citar a necessidade ou função dos profissionais de informação, em especial os Arquivistas, responsáveis pelo cumprimento de procedimentos especializados de gestão da informação e do conhecimento. Sem a presença de profissionais e procedimentos especializados, como preconizado por essa recente legislação, estão em risco os direitos cidadãos à informação.

\section{INFORMAÇÃO, ACESSO À INFORMAÇÃO E PRESERVAÇÃO DA INFORMAÇÃO}

A informação, segundo a Lei n. 12.527, de 8 de novembro de 2011 (2011), pode ser definida como "dados, processados ou não, que podem ser utilizados para produção e transmissão de conhecimento, contidos em qualquer meio, suporte ou formato". Le Coadic (1996, p.5) aborda a informação a partir da sua formalização em diferentes suportes, considerando-a como "um conhecimento inscrito (gravado) sob a forma escrita (impressa ou numérica), oral ou audiovisual". Araújo (2014) e Capurro, Hjørland, e Cardoso (2007) compreendem a informação sob três diferentes níveis de apropriação, estando os seus conceitos fundamentados em seus elementos físicos, representando a materialização da informação; cognitivos, que compreendem como o usuário apreende a informação e lhe atribui sentido; e, por último, o elemento social em que a informação é apropriada pelo sujeito cognitivo, podendo transformar esta informação e mediar o seu conhecimento adquirido.

A Lei n. 12.527, de 8 de novembro de 2011 (2011) menciona a existência de dois tipos de informações, a sigilosa e a pessoal. De acordo com o Art. 4º a informação sigilosa é "aquela submetida temporariamente à restrição de acesso público em razão de sua imprescindibilidade para a segurança da sociedade e do Estado", ou seja, é a informação que pode resultar em algum tipo de dano, material ou físico, quando revelada. E a informação pessoal, é "aquela relacionada à pessoa natural identificada ou identificável" (Lei n. 12.527, de 8 de novembro de 2011, 2011).

Esse ordenamento jurídico estabelece que é dever do Estado garantir o direito de acesso à informação pública. Bernardes (2015, p. 61) afirma que o direito de acesso à informação pública é um direito fundamental individual e coletivo, pois ele é essencial para a instrumentalização da democracia. A disponibilização do acesso à informação pública traz enormes benefícios para a sociedade, como a prevenção da corrupção, pois, ao ter acesso a informações públicas, o cidadão poderá monitorar as decisões de interesse público, embora esta mesma lei preconize e classifique algumas informações como restritas, pois podem pôr em risco a nação ou a sua população, algumas informações são sigilosas, mas com prazos para esta restrição: reservada (prazo de restrição até 5 anos, não prorrogável), secreta (prazo de restrição até 15 anos, não prorrogável), e ultrassecreta (prazo de restrição até 25 anos, prorrogável por uma única vez).

Ao contrário das bibliotecas, onde os livros danificados ou extraviados podem ser substituídos por novos exemplares, o arquivo não conta com esse benefício, pois os documentos presentes em seu acervo não são substituíveis, por isso que devem ser armazenados com o máximo de cuidado. Cassares e Moi (2000, p. 12) atribuem essa função à preservação que a conceitua como "um conjunto de medidas e estratégias de ordem administrativa, política e operacional que contribuem direta ou indiretamente para a preservação da integridade dos materiais". Ainda nesse contexto, Pereira (2011) considera as políticas de preservação como ações com o objetivo de manter a integridade dos documentos. Pode-se afirmar que a política de preservação é uma ferramenta indispensável para a manutenção de um arquivo, pois ela minimizará a deterioração dos documentos.

A informação, o acesso à informação e a preservação da informação são essenciais em uma instituição. A Instituição Federal de Sergipe e seus setores subordinados, que produzem e recebem grande volume de informação, caracteriza que o tratamento, a disseminação e a preservação da informação são aspectos essenciais para manter o controle 
das informações. O arquivo da DIPOP é um excelente exemplo de como é importante preservar e disseminar a informação.

\section{BREVE HISTÓRIA DO IFS, SETOR DA DIPOP E SEU ARQUIVO}

De acordo com o Plano de Desenvolvimento Institucional 2009-2014 (Revisado em 2012), "O Instituto Federal de Sergipe (IFS) foi criado a partir da Lei 11.892, de 29 de dezembro de 2008, com o objetivo de elevar a escolaridade brasileira a níveis de excelência" (Instituto Federal do Sergipe, 2012, p. 3). O IFS é uma instituição de ensino que oferta educação profissional e tecnológica em todos os seus níveis e modalidades. Criado com a finalidade de formar cidadãos qualificados para atuar nos diversos setores da sociedade, oferta cursos de qualificação profissional, técnicos de nível médio, superiores de tecnologia, bacharelados e licenciaturas, como também programas de pós-graduação (Instituto Federal de Sergipe, 2017). Em Sergipe, o IFS atualmente possui 08 campi espalhados pelo estado, sendo eles: Aracaju, São Cristóvão, Lagarto, Itabaiana, Estância, Glória, Propriá e Tobias Barreto.

A Diretoria de Planejamento de Obras e Projetos (DIPOP) é "responsável por planejar, coordenar, executar e avaliar conjuntamente com o Departamento de Obras e Projetos - DEOP, os projetos e atividades relacionados às demandas de infraestrutura" (Instituto Federal de Sergipe, 2016). A DIPOP é subordinada à Pró-Reitoria de Desenvolvimento Institucional (Prodin), e seus setores subordinados são a Coordenadoria de Fiscalização de Obras - CFO, e a Coordenadoria de Licitações de Obras e Serviços de Engenharia - COLENG.

O arquivo da DIPOP, especializado em engenharia e arquitetura, atualmente não possui um arquivista responsável pela sua manutenção, somente um bolsista, ligado ao Projeto de Extensão Aplicando a Gestão Documental na DIPOP. O arquivo é responsável pelo recebimento, recepção e entrada de documentos de origem interna ou externa, controle e movimentação.

Os documentos permanecem no arquivo por tempo indefinido. A documentação que não possui consulta frequente é armazenada no setor. O setor aplica alguns procedimentos para a conservação e preservação do acervo, como o controle ambiental, a proibição de consumo de alimentos e bebidas nas áreas de armazenamento, a fixação de itens soltos em pastas ou envelopes com guarda junto ao conjunto. Ou seja, quando um documento é encontrado solto, é realizada uma busca para ver se aquele item solto faz parte de algum conjunto de documentos, se sim, é então anexado junto aos outros documentos do mesmo conjunto, se não, é então armazenado em um envelope separado dos outros documentos.

O arquivo utiliza o método de arquivamento numérico e ideográfico (onde a ordenação dos documentos é feita por assunto) sendo os documentos organizados em caixas plásticas e pastas A/Z. O arquivo possui documentos textuais (memorando, processo, ofício, relatório, contrato, projeto, ata, parecer, planta, termo, portaria, planilha, e-mail, memorial, decreto), do tipo impressos e manuscritos, sendo eles cópias e originais. Vale ressaltar que o acervo possui documentos especiais (documento em linguagem não-textual, em suporte não convencional, ou, no caso de papel, em formato e dimensões excepcionais). Os documentos especiais que compõem o acervo são os materiais cartográficos (plantas) e os informáticos (mídias). Embora o arquivo possua mobiliário para a guarda dos documentos, eles não são suficientes para a guarda de todos os documentos lá presentes, além de serem inapropriados.

Por fim, o estado de conservação dos documentos é relativamente preservado, não possui nenhum problema ambiental, como fungos, roedores e insetos, ou infiltração. Entretanto, como o acervo possui documentos especiais esta conservação pode sofrer deterioração com o decorrer do tempo, por conta do armazenamento inapropriado.

\section{ATIVIDADES ESPECIALIZADAS DESENVOLVIDAS NO ARQUIVO DA DIPOP}

Atualmente o arquivo da DIPOP ainda se encontra em fase de organização. Inicialmente foi realizado um diagnóstico da situação do arquivo, onde foram analisadas as tipologias documentais (memorando, processo, ofício, relatório, contrato, projeto, ata, parecer, planta, termo, portaria, planilha, e-mail, memorial, decreto), as condições dos documentos (etapa de diagnóstico da preservação documental), o espaço físico e ambiental do arquivo (análise da área ambiental e seu espaço), verificando-se possíveis problemas de infiltração ou fungos.

O diagnóstico é uma etapa fundamental para a organização de um arquivo. Oliveira e Bedin (2018, p. 120) afirmam que "o diagnóstico é um instrumento que direciona as ações a serem tomadas, portanto, ele é determinante no processo de avaliação dos arquivos, pois mediante o seu uso é possível identificar possíveis falhas ou lacunas na gestão documental". Após o diagnóstico da situação do arquivo, foi feita a identificação dos documentos e o recolhimento dos documentos dispersos, e posteriormente a separação por assuntos dos documentos.

Após essa etapa, foi realizada a classificação dos documentos. Segundo Oliveira e Bedin (2018, p. 119), a "Classificação busca representar o documento de arquivo de acordo com a atividade e função que o gerou, visando facilitar todo o processo de recuperação da informação e acesso aos documentos". Para tal, foi utilizado o código 
de classificação de documentos de arquivo para a administração pública: atividades-meio, do Conselho Nacional de Arquivo (CONARQ), cuja resolução n. 45, de 14 de fevereiro de 2020, aprova o código. Vale ressaltar que no ano de 2020, houve uma nova atualização do Código de Classificação e Tabela de Temporalidade e Destinação de Documentos relativos às atividades-meio do Poder Executivo Federal.

Nessa nova versão, foi atualizada e padronizada a nomenclatura dos descritores, bem como a inclusão de notas explicativas para facilitar e orientar a classificação, mesmo que alguns descritores sendo autoexplicativos. Esse novo instrumento, por ter sido disponibilizado recentemente, ainda não está sendo utilizado pela Instituição Federal de Sergipe. O Código de classificação é um item essencial para a organização física dos documentos arquivados, que busca facilitar a recuperação da informação.

Posteriormente à classificação dos documentos, foi realizada a criação de uma planilha para controle e recuperação da informação. A criação de um instrumento de localização é de uma imensa importância para o controle de um arquivo, pois, com ela, o arquivo disporá de meios para controlar a saída e a entrada dos documentos, facilitará e agilizará na hora de recuperar alguma informação de seu acervo.

\section{ANÁLISE E DISCUSSÃO}

O código de classificação é uma ferramenta utilizada na organização do acervo da DIPOP. O Conselho Nacional de Arquivos (2001, p. 9) define o código de classificação como "um instrumento de trabalho utilizado para classificar todo e qualquer documento produzido ou recebido por um órgão no exercício de suas funções e atividades". Ao organizar os documentos do arquivo da DIPOP, foi utilizada a classificação por assunto (foram analisadas as funções, atividades, espécies e tipos documentais), agrupando-se os documentos de acordo com a mesma temática. Devido ao grande volume de documentos desorganizados e misturados entre diferentes espécies e tipologias, foi decidido que se começasse a separação dos documentos por espécies, tipos documentais e temas, realizar-se-ia uma separação por campi (o arquivo da DIPOP possui documentos de todos os campi do IFS), pois, assim, agilizaria a organização do acervo.

Após a separação dos documentos por campi, houve a separação das espécies, tipos documentais e temas, classificando-se posteriormente (grande parte dos documentos possuíam a classificação 041.42 - Construção), fator que corroborou com a sua característica de arquivo especializado em engenharia e arquitetura. Ressalta-se que, devido aos documentos estarem misturados uns com os outros, existiam documentos soltos que eram difíceis de se identificar e classificar por grupo. Para resolver esse problema, esses documentos sem identificação foram separados e posteriormente foram organizados e classificados, lendo seus conteúdos para ver se tinham alguma relação com os documentos já organizados (a ajuda dos engenheiros do setor também foi muito importante na hora de identificar esses documentos soltos).

Com o decorrer das atividades realizadas no acervo, foi constatado que, embora o IFS possua a Comissão Permanente de Avaliação de Documentos (CPAD) constituída pela Resolução do Conselho Superior no 20/2019/CS/IFS, ainda não houve sua efetiva atuação, pois a comissão ainda está em fase de elaboração de seu Regimento Interno. Além disso, para que seja realizado o futuro descarte do documento, o setor da DIPOP deve realizar a organização dos documentos sob sua guarda de forma eficiente.

Na etapa de organização e separação dos documentos, identificaram-se vários documentos duplicados e outros eram rascunhos, que não acrescentariam nenhum valor ao acervo, ou seja, sem valor permanente, por isso foi necessária uma política de descarte, para sanar o problema evitar que se repita no futuro. A política de descarte também contribuiu para economizar recursos do setor, diminuindo o volume de documentos e melhorando a mão de obra e os recursos necessários para a manutenção do arquivo. Uma política de descarte é de suma importância para um arquivo, pois ela evitará que o espaço seja tomado por documentos que já não têm valor primário para a instituição.

Embora a instituição utilize a tabela de temporalidade atividade-meio da Administração Pública, o setor não a utiliza para definir a temporalidade dos documentos. O tempo de guarda dos documentos do arquivo da DIPOP não é respeitado, a exemplo, o arquivo possui vários documentos que já extrapolaram o tempo de guarda, mas que ainda permanecem armazenados no setor.

Vale ressaltar que a tabela de temporalidade e a política de descarte estão relacionadas, pois a tabela de temporalidade define o prazo do documento e seu ciclo de vida, e posteriormente a sua destinação, se irá ser mandado para o arquivo intermediário, permanente ou para o descarte (que é onde entra a política de descarte).

Mesmo sem uma política de descarte de documentos e o uso ineficiente da tabela de temporalidade, pode-se observar que a Gestão Documental contribuiu e ainda vem contribuindo na administração do arquivo da DIPOP. A Gestão Documental ajudou a otimizar o ambiente do arquivo, pois, através da organização dos documentos, foi possível utilizar de maneira mais eficiente o espaço limitado do arquivo e potencializou a recuperação da informação. 


\section{CONSIDERAÇÕES FINAIS}

O Arquivo tem a função de recolher, ordenar, avaliar, selecionar, arquivar, conservar e assegurar a integridade dos documentos, visando a preservação e a disseminação da informação que está contida em seu acervo. Ao inserir a Gestão Documental em arquivos constitui um processo essencial para a normatização, organização, tratamento e recuperação dos documentos, favorecendo para que o documento cumpra a sua função administrativa, probatória e arquivística. Além disso, os arquivos possuem como característica enaltecer e preservar a memória e a história da instituição, fator de grande relevância social. Ao longo dos estudos desenvolvidos, foi possível compreender de forma mais clara e concisa os conceitos de gestão documental, gestão da informação, mediação explícita e implícita, informação, acesso à informação e preservação da informação. Esse referencial teórico apoiou a caracterização e compreensão de maneira mais clara e sucinta todas as atividades que foram e ainda vêm se desenvolvendo no arquivo da DIPOP.

Identificaram-se diálogos sobre a função da mediação da informação promovida pelos profissionais arquivistas, de maneira explícita ou implícita que implica no novo fazer do profissional da informação. Destacam-se, ainda, diálogos sobre a importância de equipes multidisciplinares, conhecimento do perfil dos usuários reais e potenciais para viabilizar a mediação, a gestão da informação, apropriação da informação e construção do conhecimento. Entende-se que todo o processo de gestão da informação caracteriza o arquivo como unidade de informação, potencializa mudanças caracterizadas pelo paradigma pós-custodial e torna o acesso à informação e construção do conhecimento especializado em Arquitetura e Engenharia como objetivos primordiais dos serviços especializados prestados.

Observou-se que as aplicações práticas desenvolvidas no arquivo da DIPOP possibilitaram associar as teorias arquivistas em um ambiente social aplicado e que todas as ações de organização de um arquivo estão hierarquicamente subordinadas à sua organização ou unidade produtora e receptora da massa documental. Ao se aplicar a gestão especializada, pode se estruturar uma unidade de informação especializada, contemplando-se o regime e as necessidades informacionais dos seus usuários.

Observaram-se as diferentes tipologias documentais características do arquivo especializado em arquitetura e engenharia caracterizadas por variedades de suportes tradicionais e digitais (mapas, plantas, maquetes, artefatos, levantamentos topográficos, hipsográficos, geidrográficos, entre outros). Os profissionais da informação envolvidos, necessariamente em equipe multidisciplinar, compreenderam as necessidades de guarda, manejo, consulta, na dicotomia que envolve a digitalização, manejo digital, impressão, plotagem, migração de documentos entre suportes e programas com aplicação de diferentes artefatos, equipamentos, recursos.

Tendo em vista os aspectos observados, percebe-se que a profissionalização da equipe, a aplicação da Gestão da Informação e do Conhecimento, da Gestão Documental e da mediação informacional especializada no arquivo da DIPOP alteraram positivamente a concretização de objetivos informacionais no Arquivo Especializado em Arquitetura e Engenharia. A importância dessa unidade de informação transcende os muros do IFS, gerando efeitos no conhecimento especializado de toda a comunidade de prática de Arquitetura e Engenharia do estado de Sergipe. Por falar em cultura sergipana, a função social da universidade pública e de qualidade é enfatizada pela experiência da gestão da informação especializada, quando a política de administração acadêmica do IFS toma por base princípios científicos na gestão de processos especializados de informação em sua estrutura. 


\section{REFERÊNCIAS}

Araújo, C. A. Á. (2014). O que é ciência da informação. Informação \&̧ Sociedade, 20(3), 95-105. Recuperado de https://periodicos.ufpb.br/ojs/index.php/ies/ article/view/6951.

Arquivo Nacional. (2005). Dicionário brasileiro de terminologia arquivística. (n. 51). Rio de Janeiro: Arquivo Nacional.

Bellotto, H. L. (2007). Arquivos permanentes: tratamento documental. (2.ed. ed.). São Paulo: TA Queiroz.

Bernardes, C. F. S. (2015). O direito fundamental de acesso à informação: uma análise sob a ótica do princípio da transparência. (Dissertação de mestrado, Universidade Federal de Uberlândia, Uberlândia, MG, Brasil). Recuperado de https://repositorio.ufu.br/bitstream/123456789/13238/ 3/DireitoFundamentalAcesso.pdf.

Capurro, R., Hjørland, B., \& Cardoso, A. M. P. (2007). O conceito de informação. Perspectivas em Ciência da Informação, 12(1), 148-207. Recuperado de http://portaldeperiodicos.eci.ufmg.br/index.php/pci/ article/view/54/47.

Cassares, N. C., \& Moi, C. (2000). Como fazer conservação preventiva em arquivos e bibliotecas. São Paulo: Arquivo do Estado; Imprensa Oficial.

Conselho Nacional de Arquivos. (2001). Classificação, temporalidade e destinação de documentos de arquivo relativos às atividades-meio da administração pública. Brasília: Arquivo Nacional. Recuperado de http://www.siga.arquivonacional.gov.br/images/ publicacoes/cctt_meio.pdf.

Decreto n. 10.278 de 18 de março de 2020. (2020). Regulamenta o disposto no inciso $x$ do caput do art. $3^{\circ}$ da lei $n$. 13.874, de 20 de setembro de 2019, e no art. $2^{\circ}$ - a da lei $n$. 12.682, de 9 de julho de 2012, para estabelecer a técnica e os requisitos para a digitalização de documentos públicos ou privados, a fim de que os documentos digitalizados produzam os mesmos efeitos legais dos documentos originais e dá outras providências. Brasília: Diário Oficial da União. Recuperado de http://www.planalto.gov.br/ccivil_03/_ato2019-2022/ 2020/decreto/D10278.htm.

Fadel, B., Almeida, C. C. d., Casarin, H. d. C. S., Valentim, M. L. P., Almeida Júnior, O. F. d., \& Belluzzo, R. C. d. A. (2010). Gestão, mediação e uso da informação. In M. L. P. Valentim (Ed.), Gestão, mediação e uso da informaçã (p. 13-22). São Paulo: Cultura Acadêmica.

Franklin, S. (2007). Arquivos técnicos: conceitos e características. Salvador, BA: UFBA/ICI/DDI.

Instituto Federal do Sergipe. (2012). Plano de desenvolvimento institucional 2009 a 2014 (revisado em 2012). Aracaju: IFS. Recuperado de http://www.ifs.edu.br/prodin/ images/banners/pdi_planejamento_estrategico.pdf.

Le Coadic, Y. F. (1996). A ciência da informação. Brasília: Briquet de Lemos.

Lei n. 12.527, de 8 de novembro de 2011. (2011). Regula o acesso a informações previsto no inciso xxxiii do art. $5^{\circ}$, no inciso ii do parágrafo $3^{\circ}$ do art. 37 e no parágrafo $2^{\circ} d o$ art. 216 da constituição federal; altera a lei n. 8.112, de 11 de dezembro de 1990; revoga a lei $n$. 11.111, de 5 de maio de 2005, e dispositivos da lei $n$. 8.159, de 8 de janeiro de 1991 e dá outras providências. Brasília: Diário Oficial da União. Recuperado de http://www.planalto.gov.br/ccivil _03/_ato2011-2014/2011/lei/112527.htm.
Lei n. 8.159, de 8 de janeiro de 1991. (1991). Dispõe sobre a política nacional de arquivos públicos e privados e dá outras providências. Brasília: Presidência da República. Recuperado de http://www.planalto.gov.br/ccivil_03/Leis/ L8159.htm.

Lutz, C. C., \& Somavilla, R. (2016). Tratamento documental em arquivo especializado: projetos de arquitetura e engenharia da universidade federal de santa catarina. Revista Analisando em Ciência da Informação, 4(esp), 857-872. Recuperado de http://racin.arquivologiauepb.com.br/edicoes/ v4_nesp/racin_v4_nesp_artigo_0857-0872.pdf.

Moreno, N. A. (2008). Gestão documental ou gestão de documentos: trajetória histórica. In L. Bartalo \& N. A. Moreno (Eds.), Gestão em arquivologia: abordagens múltiplas. Londrina, PR: EDUALE.

Oliveira, T. M. M. d., \& Bedin, S. P. M. (2018). Diagnóstico de arquivo como instrumento de avaliação na gestão documental. Ágora, 28(56), 115-135. Recuperado de https://agora.emnuvens.com.br/ra/article/view/674.

Paes, M. L. (2004). Arquivo: teoria e prática (2.ed. rev. e ampl. ed.). Rio de Janeiro: Editora da FGV.

Pereira, F. M. (2011). ). preservação da informação em instituições da administração pública brasileira. (Dissertação de mestrado). Universidade de Brasília, Brasília, DF, Brasil.

Schmidt, C. M. d. S. (2012). Arquivologia e a construção do seu objeto científico: concepções, trajetórias, contextualizações. (Tese de doutorado, Universidade de São Paulo, São Paulo, SP, Brasil). Recuperado de https://www.teses.usp.br/teses/disponiveis/27/27151/ tde-02072013-170328/pt-br.php

Tavares, D. W. d. S., \& Loureiro, O. J. M. M. (2017). Dispositivos de informação: arquivos, memórias e informação. TransInformação, 29(1), 73-80. doi: 10.1590/231808892017000100007

Universidade Estadual de Campinas. (2005). Manual técnico organização de arquivos correntes e intermediários. Campinas, SP: Unicamp. Recuperado de https://www.siarq.unicamp.br/siarq/images/ siarq/pesquisa/textos_tecnicos/organizacao_arquivos _correntes_intermediarios.pdf.

Woida, L. M. (2008). Cultura informacional: um modelo de realidade social para a ico. In M. L. P. Valentim (Ed.), Gestão da informação e do conhecimento. São Paulo: Polis; Cultura Acadêmica.

Como citar este artigo (APA):

Santos, F. G. S. dos, Silva, M. do N., \& Bari, V. A. (2021). O impacto da gestão documental nos arquivos de engenharia e arquitetura: uma análise do arquivo da DIPOP do Instituto Federal de Educação, Ciência e Tecnologia de Sergipe. AtoZ: novas práticas em informação e conhecimento, 10(1), 85 - 93. Recuperado de: http://dx.doi.org/10.5380/atoz.v10i1.75160 